\title{
Recent Surface Air Temperature Change over Mainland China Based on an Urbanization-Bias Adjusted Dataset
}

\author{
KANGMIN Wen, ${ }^{\mathrm{a}}$ GUOYU Ren,,${ }^{\mathrm{a}, \mathrm{b}}$ JiAO Li,${ }^{\mathrm{c}}$ AIYING ZHANG, ${ }^{\mathrm{d}}$ YUYU ReN, ${ }^{\mathrm{b}}$ \\ XIUBAO SUn, ${ }^{a, b, e}$ AND YAQING ZHOU ${ }^{\mathrm{f}}$

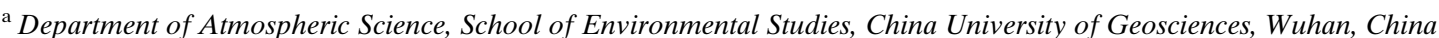 \\ ${ }^{\mathrm{b}}$ Laboratory for Climate Studies, National Climate Center, China Meteorological Administration, Beijing, China \\ ${ }^{\mathrm{c}}$ Tieling Meteorological Bureau, Liaoning Province, Tieling, China \\ ${ }^{\mathrm{d}}$ Beijing Meteorological Bureau, Beijing, China \\ ${ }^{\mathrm{e}}$ College of Atmospheric Science, Nanjing University of Information Science and Technology, Nanjing, China \\ ${ }^{\mathrm{f}}$ Jinzhong Meteorological Bureau of Shanxi Province, Jinzhong, China
}

(Manuscript received 20 June 2018, in final form 16 February 2019)

\begin{abstract}
A dataset from 763 national Reference Climate and Basic Meteorological Stations (RCBMS) was used to analyze surface air temperature (SAT) change in mainland China. The monthly historical observational records had been adjusted for urbanization bias existing in the data series of size-varied urban stations, after they were corrected for data inhomogeneities mainly caused by relocation and instrumentation. The standard procedures for creating area-averaged temperature time series and for calculating linear trend were used. Analyses were made for annual and seasonal mean temperature. Annual mean SAT in mainland China as a whole rose by $1.24^{\circ} \mathrm{C}$ for the last 55 years, with a warming rate of $0.23^{\circ} \mathrm{C}$ decade $^{-1}$. This was close to the warming of $1.09^{\circ} \mathrm{C}$ observed in global mean land SAT over the period 1951-2010. Compared to the SAT before correction, after-corrected data showed that the urbanization bias had caused an overestimate of the annual warming rate of more than $19.6 \%$ during 1961-2015. The winter, autumn, spring, and summer mean warming rates were $0.28^{\circ}, 0.23^{\circ}, 0.23^{\circ}$, and $0.15^{\circ} \mathrm{C}$ decade ${ }^{-1}$, respectively. The spatial patterns of the annual and seasonal mean SAT trends also exhibited an obvious difference from those of the previous analyses. The largest contrast was a weak warming area appearing in central parts of mainland China, which included a small part of southwestern North China, the northwestern Yangtze River, and the eastern part of Southwest China. The annual mean warming trends in Northeast and North China obviously decreased compared to the previous analyses, which caused a relatively more significant cooling in Northeast China after 1998 under the background of global warming slowdown.
\end{abstract}

\section{Introduction}

One of the core issues of contemporary climate change research is global and subcontinental surface air temperature (SAT) change. In mainland China, the climate observational network is not dense enough in some remote areas and data gaps are a serious problem prior to 1951 , and there is a large uncertainty in estimating changes and long-term trends for SAT over the past 100 years. Hence, in order to better understand the detailed temporal and spatial structure in modern SAT change in mainland China, many researchers have turned to analyze the high-quality and high-density observational network records of recent decades.

Corresponding author: Guoyu Ren, guoyoo@cma.gov.cn
Researchers had used varieties of methods to analyze the SAT change over mainland China since the late of 1980s, but most of these works did not consider the inhomogeneities in SAT data (Qiao and Qin 1990; Zhao et al. 1990; Chen et al. 1991; Lin et al. 1995; Chen and Zhu 1998; Zhai and Ren 1999; Qian and Lin 2004; Wang et al. 2004; Huang et al. 2005; Qian and Qin 2005). Since 2005, homogenized datasets obtained by various methods were used to analyze the land SAT changes over mainland China. Thus, the discontinuities in historical observational data, such as instrumentation and relocation of stations, had been corrected to some extent.

Ren et al. (2005a,b) analyzed spatial and temporal characteristics of annual- and seasonal-mean SAT changes during 1951-2004 by using monthly mean SAT data from 740 national Reference Climate and Basic 
Meteorological Stations (RCBMS, or national stations) across mainland China, for example, and they found that the annual-mean SAT increased with a rate of $0.25^{\circ} \mathrm{C} \mathrm{decade}^{-1}$ up to 2004 , and the warming across the country mainly appeared after the mid-1980s. Tang et al. (2005) compared the SAT change of eastern China with that of western China during 1951-2002, showing that the spring and winter mean SAT of eastern China increased more significantly than those in western China, but the summer and autumn warming of eastern China were not as obvious as that of western China. Cao et al. (2016) analyzed annual- and seasonal-mean SAT variations in mainland China during 1960-2014 by utilizing a homogenized dataset of 2400 stations. They found that the annual-mean maximum SAT increased with a rate of $0.22^{\circ} \mathrm{C}$ decade $^{-1}$ and the annual-mean SAT increased with a rate of $0.38^{\circ} \mathrm{C}$ decade ${ }^{-1}$, which were significantly larger than the rates estimated by the previous analyses (Ren et al. 2005a,b; Ding and Ren 2008).

Ren et al. (2016) studied the temporal and spatial variations of SAT during 1973-2011 in mainland China by utilizing an hourly temperature dataset. They concluded that the annual-mean SAT of the whole country increased rapidly at night until 1992, with rapid warming often occurred around midnight. However, rapid warming during the daytime happened after 1992, with the strongest warming appeared in the later afternoon. Li et al. (2015) and Sun et al. (2017a) found the phenomenon of warming slowdown over mainland China, in particular even a cooling trend in Northeast China, after 1998. In Northeast China, the cooling trend was the most remarkable in the cold season including winter and spring (Sun et al. 2017a).

On regional and subcontinental scales, however, urbanization, including the strengthened urban heat island (UHI) effect, has been confirmed to exert significant impacts on the estimated trends at many meteorological stations and the regional-averaged SAT series, including those studies for mainland China.

Zhou et al. (2004) estimated warming of mean surface temperature of $0.05^{\circ} \mathrm{C}$ decade $^{-1}$ attributable to urbanization based on analysis of impacts of land-use changes on surface temperature in southeast China, where rapid urbanization has occurred. Ren et al. (2005c, 2008) pointed out that the increasing of annual mean SAT induced by urbanization for national stations reaches $0.44^{\circ} \mathrm{C}$ during $1961-2000$ in North China, which experienced the most remarkable warming in the country, with an increasing rate of SAT reached $0.11^{\circ} \mathrm{C}$ decade $^{-1}$, accounting for $38 \%$ of the total warming trend as recorded by these stations. Tang et al. (2008) analyzed the effect of urbanization to the SAT changes during 1961-2004 in southwest China, and found that the warming rates of town and city stations, and national stations on a whole, were greater than those at rural stations. In annual mean SAT records of national stations, urban warming trend was estimated as $0.05^{\circ} \mathrm{C} \mathrm{decade}^{-1}$, and its contribution to overall annual mean SAT trend was $45.3 \%$. Hua et al. (2008) investigated the variations of annual and seasonal mean SAT during 1961-2000 in mainland China due to urbanization. They found that there was a positive correlation between urban population and the rate of urban warming. The northern stations showed a stronger urban warming than the southern stations. According to the metadata of specific locations of the stations and the population of residential areas near observational sites, Zhou and Ren (2009) classified the stations in northern China into five categories to examine the urbanization effect retained in the observed SAT records. They showed that all of the categories underwent a warming in terms of average SAT and minimum SAT, with the national stations and all categories of urban stations experiencing larger increase in annual mean SAT than that of the rural stations.

Yang et al. (2011) pointed out that UHI effects contributed $24.2 \%$ to regional average warming trends over eastern China, and the strongest effect of urbanization on annual mean SAT trends occurred over the metropolis and large city stations, with corresponding contributions to total warming were $44.0 \%$ and $35.0 \%$, respectively, during 1981-2007. Wang and Ge (2012) reported that the urbanization effect was $0.09^{\circ} \mathrm{C}$ decade $^{-1}$ and accounted for $20.0 \%$ of the total warming over mainland China. He et al. (2013) found that the warming caused by urbanization contributed to about $44.1 \%$ of the total increasing rate during 1978-2008 in the plain area of North China. Sun et al. (2017b) suggested that the urbanization effects on the SAT trends in varied periods and regions and the unevenly and sparsely distributed data in the early years might have posed the greatest problems in the present estimates of global and regional average SAT change over the last century.

The first attempt to examine the effect of urbanization in mainland China on a whole was carried out by Zhang et al. (2010) by using a homogenized dataset and a reference station network as reported in Ren et al. (2015). They confirmed that the urbanization effect contained in the warming trend of annual mean SAT of the national stations during 1961-2004 for mainland China was at least $0.08^{\circ} \mathrm{C}$ decade $^{-1}$. This impact was highly significant statistically, and the contribution of urbanization exceeded $27.3 \%$. Ren et al. (2015) reported a comprehensive procedure for determining reference stations for evaluating urbanization effects recorded at urban stations, and estimated the urbanization effect and contribution in the 
SAT data series of the Chinese national stations. They showed a highly significant urbanization effect of $0.07^{\circ} \mathrm{C}$ decade $^{-1}$ and an urbanization contribution of $24.9 \%$ for the national stations of the country during the time period 1961-2004, which compared well to the results previously reported by Zhang et al. (2010).

The urbanization effect contained in the extreme temperature indices series of national stations was assessed by Ren and Zhou (2014) by utilizing the reference network data that were developed by Ren et al. (2015) and used in Zhang et al. (2010), showing that urbanization effects on the long-term trends of annual and seasonal mean minimum SAT (Tmin), average SAT (Tavg), diurnal temperature range (DTR), and the extreme SAT indices commonly used internationally were larger in mainland China during 1961-2008. In particular, the urbanization effects on the downward trend of DTR and the upward trend of Tmin were highly significant, with the urbanization contribution for annual mean DTR trend exceeding 32\% over mainland China. This suggests that the urbanization effect not only exists to a great extent in the mean SAT trends on the subcontinental scale but also is not ignorable in the time series of the extreme temperature indices. Sun et al. (2016) made an attribution analysis on the basis of a dataset of 2400 stations and found that $1 / 3$ of the overall increase of annual mean SAT in mainland China during the half century was attributable to the urbanization effect.

Therefore, the regional average SAT trends in mainland China obtained by previous studies, mostly based on the dataset of the RCBMS (Ren et al. 2008, 2012), contained great bias due to the urbanization effect. Although there existed a divergence among the estimates of the urbanization effect, the majority of the previous works, especially of those based on more sophisticated and objective procedures to select reference stations (e.g., Ren et al. 2008, 2015; Zhang et al. 2010; Yang et al. 2011; Wang and Ge 2012; He et al. 2013), were in favor of an urbanization contribution around $20.0 \%$ for annual-mean SAT trends of the RCBMS for the last half century for the country.

Hence, urbanization effect have exerted significant impacts on SAT records and the estimated trends at most of the RCBMS as well as on the regionally averaged SAT series in mainland China, and it is now desirable to quantify the urbanization biases and more importantly to remove them from the homogenized RCBMS dataset before it is used for studying the regional average SAT change. The obtained urbanization-bias adjusted dataset will play its due role in promoting studies of climate change detection and attribution and climate model validation, and also in conducting studies of regional climate change impact and vulnerability assessment.

Recently, Wen et al. (2019) developed a method for correcting the urbanization biases in monthly mean SAT dataset of the urban stations network, and made an effort to adjust the urbanization biases for each national station in mainland China. An urbanization-bias adjusted dataset has been finally constructed. In this study, we utilize the urbanization-bias adjusted dataset to analyze the SAT change in mainland China, so as to obtain a better understanding of SAT changes over mainland China over the past decades.

\section{Data and methods}

\section{a. Data sources}

An urbanization-bias adjusted monthly SAT dataset of 763 national stations during 1961-2015 was used here to analyze SAT change in mainland China. The data were adjusted for urbanization bias of different categories of urban stations by applying a new adjusted method (Wen et al. 2019), after it had been homogenized by the National Meteorological Information Center (Li 2011; Cao et al. 2016).

The data source for urbanization bias correction is the homogenized monthly mean SAT dataset, which is from the National Meteorological Information Center (NMIC), China Meteorological Administration (CMA). It consists of a total of about 2400 meteorological stations, with $34.4 \%$ of observation sites coming from RCBMS (national stations), and $65.6 \%$ from ordinary weather stations. In the field of climate change monitoring and research in mainland China, the mostly frequently applied SAT data were from RCBMS datasets (Ren et al. 2008, 2012). Therefore, the urbanization biases corrections were made to the monthly temperature data of RCBMS (Wen et al. 2019).

Considering the lack of temperature data before 1961 and after 2015, the time range from 1961 to 2015 was selected. It was stipulated that the missing rate of data could not exceed $2 \%$ during the period 1961-2015, and there are 763 RCBMS that meet the criterion (Fig. 1a). For the missing values (less than $2 \%$ in the target stations), the monthly mean values of the 10 years ( 5 years before and 5 years after the missing years respectively) were used to fill up the gaps. This guarantees that the filled monthly mean values fall within the decadal averages.

\section{b. Reference stations for mainland China}

A key to assess and adjust the urbanization bias is the development of a surface air temperature dataset of 

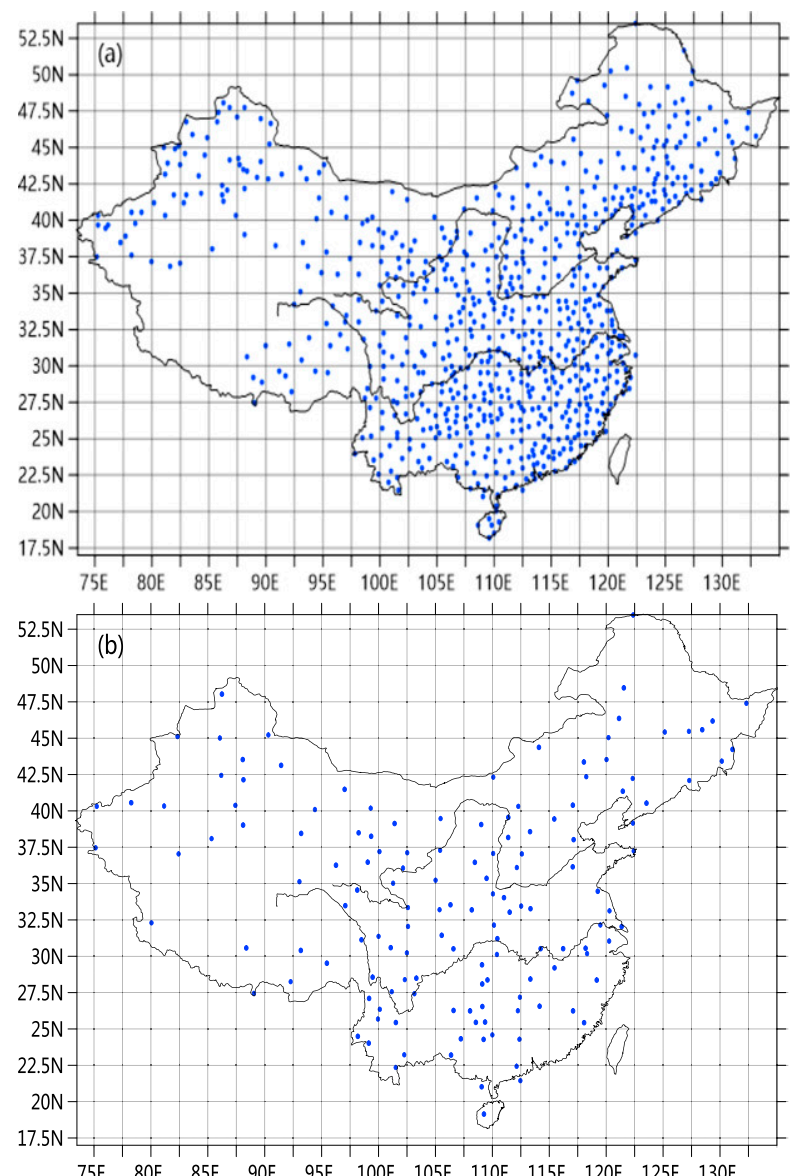

75E $80 \mathrm{E} \quad 85 \mathrm{E}$ 90E $95 \mathrm{E}$ 100E $105 \mathrm{E}$ 110E $115 \mathrm{E}$ 120E $125 \mathrm{E}$ 130E

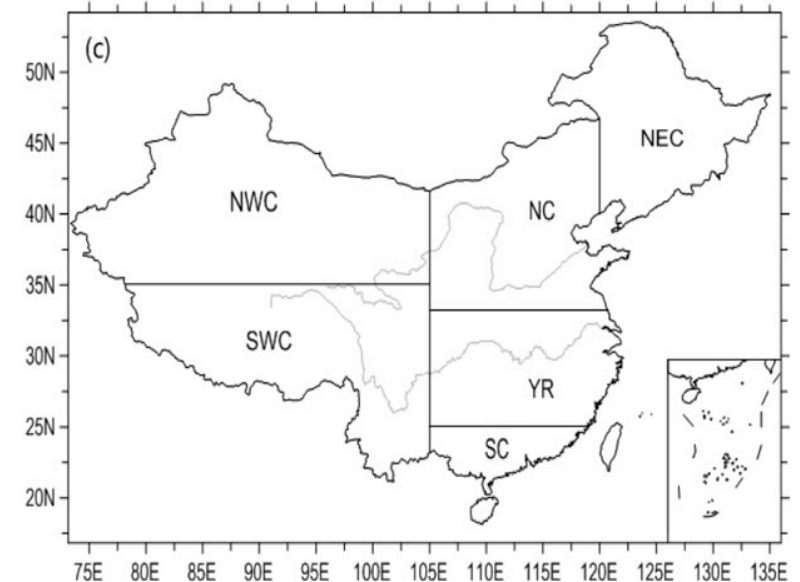

FIG. 1. (a) Distribution of 763 national stations and (b) 143 reference stations distributed in the grid of $2.5^{\circ}$ latitude $\times 2.5^{\circ}$ longitude in mainland China, and (c) boundaries of the divided six subregions. NEC, NC, NWC, SWC, YR, and SC represent Northeast China, North China, Northwest China, Southwest China, the middle to lower Yangtze River valley, and South China, respectively. reference stations (rural stations). The reference stations network developed in previous studies (Ren et al. 2010, 2015; Zhang et al. 2010) was used to adjust the urbanization biases in RCBMS data in this work. According to Ren et al. (2010, 2015), the reference stations were selected from 2400 observational stations (RCBMS and ordinary weather stations) across the country. The criteria and steps used for selecting the reference stations were as follows:

1) Candidate reference stations had records of more than 50 years, with the beginning of record being no later than 1961, and without any missing records. In all, 1330 stations met these criteria.

2) Furthermore, 332 stations were selected from the 1330 candidate stations with the consideration that the permanent population of the settlements near the stations was less than 20000 in 2000 , but less than 70000 in plain areas of eastern China.

3) The number of relocations had to be less than 3 after 1961, and the horizontal distances for the relocations were less than $5 \mathrm{~km}$ in plains and plateau areas. After this round of selection, 245 stations were remained.

4) The circumambient environment of the 245 stations was examined to guarantee the relative proportion of the built-up area within the circular of $2-\mathrm{km}$ radius less than $33.0 \%$. Only 148 stations were kept after this round of selection.

5) Five stations were discarded because they were too close to others. Finally, 143 stations were kept as the reference stations (Fig. 1b).

Based on the data of the reference stations, previous analyses (Zhang et al. 2010; Ren et al. 2015) assessed the urbanization effect (urbanization bias) and contribution in the monthly mean SAT data series of the RCBMS data. Referring to the methods in Ren et al. (2015), we updated the calculation urbanization biases for the 684 national stations in mainland China for the period 19612015. Figure 2 shows the spatial distribution of urbanization biases on basis of stations. The areas with large urbanization biases were distributed in northern and eastern China, including North China, parts of central China, the northern parts of Northeast China, East China, and parts of the Qinghai-Tibetan Plateau, with the values ranging from $0.10^{\circ}$ to $0.30^{\circ} \mathrm{C}$ decade $^{-1}$. The negative urbanization biases appeared in parts of Northwest China and the western and the southern Qinghai-Tibetan Plateau, probably due to the effect of oasis expansion in the urban areas of the arid and semiarid regions (Zhang et al. 2010; Ren et al. 2015). A few of the national stations located in south of Northeast China, South China coastal areas, and central China also showed small negative urbanization bias. 


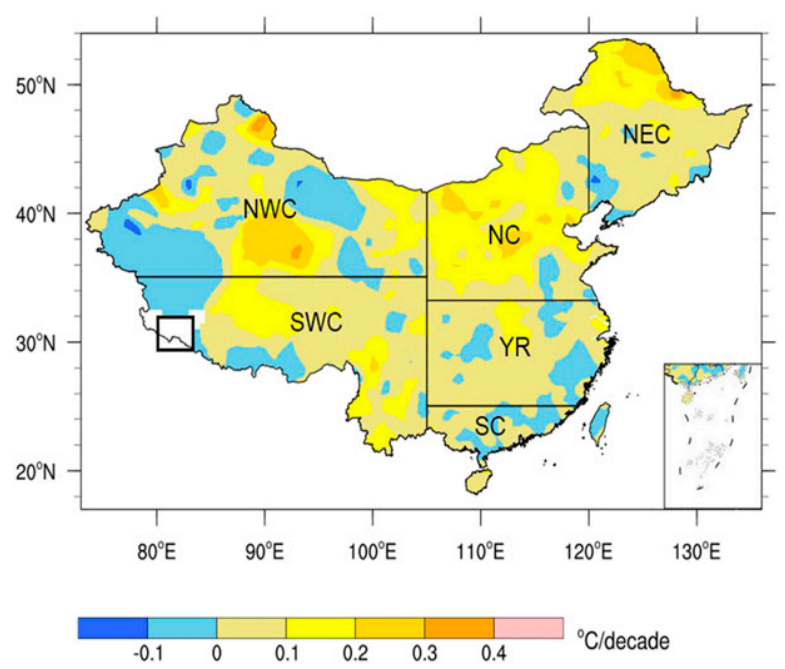

FIG. 2. Distribution of urbanization biases for 684 national stations in mainland China. A black box indicates lack of data.

\section{c. Reference stations and series for target stations}

Among all of the reference stations, there were 79 national stations and 64 ordinary stations. The 79 national stations of the reference stations network did not need adjustment for urbanization bias. In addition, Xisha station, which is located in the South China Sea near Hainan Province, was not considered for adjustment because there were no proper reference stations within $300 \mathrm{~km}$. Finally, data of total 684 national stations or RCBMSs were corrected for urbanization biases. To compare urban-rural differences on a subcontinental scale like that of mainland China, we must take the large-scale patterns of climate change into consideration. In addition, we had to take into account the density and distribution of the reference stations in order to ensure that each target station could still have at least one reference station in the areas where reference stations were distributed relatively sparsely. Therefore, we stipulated that the reference stations chosen could not exceed $300 \mathrm{~km}$ from their target stations; that is, the reference stations had to be within the large circles of $300-\mathrm{km}$ radius with the target stations as centers.

In establishing the specific reference stations for each target station, we referred to the method developed for testing the spatial consistency of climate records in data quality control (Karl and Williams 1987; Mitchell and Jones 2005; Li 2011). A station within a circle with a fixed radius centered on an urban station was used as a reference observational site for the urban station. The distance between two stations was calculated by using the following formula [Eq. (1)]:

$$
\begin{aligned}
d\left(A_{1}, A_{2}\right)= & R \cos ^{-1}\left[\sin \varphi_{1} \sin \varphi_{2}\right. \\
& \left.+\cos \varphi_{1} \cos \varphi_{2} \cos \left(\theta_{1}-\theta_{2}\right)\right],
\end{aligned}
$$

where $\theta_{1}$ and $\varphi_{1}$ are the longitude and latitude of station $A_{1}, \theta_{2}$ and $\varphi_{2}$ are the longitude and latitude of station $A_{2}$, and $R$ is the radius of Earth $(6371 \mathrm{~km})$.

To obtain reference stations for arbitrary target stations in the northeast, central, and western regions of the Qinghai-Tibetan Plateau where the reference stations are distributed more sparsely, we adopted a method of iterative correction that first adjusted the target stations from east to west for each longitudes, and the target stations after correcting urbanization bias then could also serve as reference stations.

After stipulating the distance between the target stations and the reference stations and selecting the candidate reference stations of any target stations, a further consideration was made as to whether the interannual and interdecadal SAT variability of the candidate reference stations were consistent with the target stations, or whether they were located in the same zones of climate variability. Therefore, the correlation coefficient of the annual mean temperature at the two stations after removing the linear trend was used as an indicator of the variability similarity. The series that removed linear trend mainly reflected the variability of SAT on interannual and interdecadal scales. The linear trend was obtained by one-dimensional linear regression analysis. If the correlation coefficients of the detrended annual mean temperature series between each target station and the nearby candidate reference stations passed a $p=$ 0.005 significance level test, then the candidate reference stations were selected as the final reference stations for the target station. To adjust the urbanization bias of RCBMS data, it was important to construct a reference series for each of the target stations. Studies (e.g., Yu et al. 2012) found that, for the interpolation of missing SAT data at any station, the interpolated values calculated by the four neighboring stations with the highest correlation were highly accurate. Other studies (e.g., Jiang et al. 2008) showed that, in the correction of the inhomogeneity of precipitation data series in mainland China, the reference series could be constructed by using the data of three stations with the highest correlation coefficients among the closest 20 stations. Referring to these methods, and taking into account that an excessive number of reference stations involved in the calculation will lead to significant error, we stipulated that, when the number of reference stations of a target station is more than four, four stations with the highest correlation coefficients with the target station annual mean temperature were taken as the final reference stations, but the 
TABLE 1. Number of stations with different adjusted temperature magnitude and their percentages.

\begin{tabular}{|c|c|c|c|c|c|c|c|c|}
\hline $\begin{array}{l}\text { Adjusted temperatures } \\
\qquad\left({ }^{\circ} \mathrm{C} \text { decade }{ }^{-1}\right)\end{array}$ & -0.3 to -0.2 & -0.2 to -0.1 & -0.1 to 0 & 0 to 0.1 & 0.1 to 0.2 & 0.2 to 0.3 & 0.3 to 0.4 & 0.4 to 0.5 \\
\hline No. of stations & 1 & 15 & 187 & 289 & 139 & 48 & 4 & 1 \\
\hline Percentage (\%) & 0.15 & 2.19 & 27.34 & 42.25 & 20.32 & 7.02 & 0.58 & 0.15 \\
\hline $\begin{array}{l}\text { Cumulative } \\
\text { percentage }(\%)\end{array}$ & - & 2.34 & 29.68 & 71.93 & 92.25 & 99.27 & 99.85 & 100 \\
\hline
\end{tabular}

candidate reference stations were all retained when there were fewer than four.

To obtain the reference series of monthly mean SAT for each target station, the weighted averages of monthly mean SATs of all reference stations of the target station were calculated by using the squares of correlation coefficients of monthly mean SAT series between the reference stations and the target station as the weights. The formula for calculating the reference series for each target station is [Eq. (2)]

$$
T=\frac{\sum_{i=1}^{m}\left(C_{i}^{2} \times T_{i}\right)}{\sum_{i=1}^{m}\left(C_{i}^{2}\right)},
$$

where $T$ is the monthly mean SAT of reference series, $i=$ $1,2, \ldots, m$ ( $m$ is the number of reference stations), $C_{i}$ denotes the correlation coefficient of monthly mean SAT series between reference station $i$ and the target station, and $T_{i}$ is the monthly mean SAT of reference station $i$.

\section{d. Method of adjustment}

Based on the method of linear correction (Zhou and Ren 2005; Zhang 2009), urbanization bias at the target station was adjusted by using the linear trend difference of SAT between the target station and the reference series as the total correction. The procedure was based on two assumptions: 1) the linear trend of the established reference series of a target station represented the regional background temperature trends, and 2) the effect of urbanization on the trend of the target station mean SAT series was linear; that is, the effect was similar in different years and decades. The urbanization bias in SAT series of the target station was actually removed on the annual basis.

The correcting method is to add the yearly correction ( $X / n$, with $X=$ total correction, and $n=$ length of the data series) from the second-last year to the first year of the data series year by year for the target station, with the recorded value of the last year (2015) kept unchanged [Eq. (3)]:

$$
T_{i}^{\prime}=T_{i}+\left(\Delta T_{u-r} / 10\right)(k-i),
$$

where $T_{i}^{\prime}$ is the temperature corrected in year $i, T_{i}$ is the temperature in year $i$ before correction, $\Delta T_{u-r}$ is the urbanization bias during the study period $\left({ }^{\circ} \mathrm{C}\right.$ decade $\left.^{-1}\right)$, and $k$ is the ending year of the temperature series. The corrected series put the temperature data in the last year and the coming years as the fixed values, and thus would have a better extensibility.

Table 1 showed the number of stations with different adjusted temperature magnitudes and their percentages. The adjusted temperature magnitudes of $-0.10^{\circ}$ to $-0.05^{\circ},-0.05^{\circ}$ to $0^{\circ}, 0^{\circ}$ to $0.05^{\circ}, 0.05^{\circ}$ to $0.10^{\circ}, 0.10^{\circ}$ to $0.15^{\circ}$, and $0.15^{\circ}$ to $0.20^{\circ} \mathrm{C}$ decade ${ }^{-1}$ accounted for larger proportion, and possessed a total number of 615 stations, accounting for $89.91 \%$ of all the national stations adjusted. There were 80 national stations that did not need to be adjusted for urbanization biases. Figure 3 shows the variation for number of stations with different adjusted temperature magnitudes. The number of stations increased after the temperature magnitude of $0^{\circ} \mathrm{C}$ decade $^{-1}$, and the maximum number of stations (226) was reached between $0^{\circ}$ and $0.05^{\circ} \mathrm{C}$ decade $^{-1}$. With the increase of the absolute values of the adjusted temperature magnitudes, the numbers of stations gradually reduced.

\section{e. Method of trend analysis}

Based on the adjusted monthly mean temperature data, we reanalyzed the long-term changes in annual and seasonal mean SAT over mainland China for the period

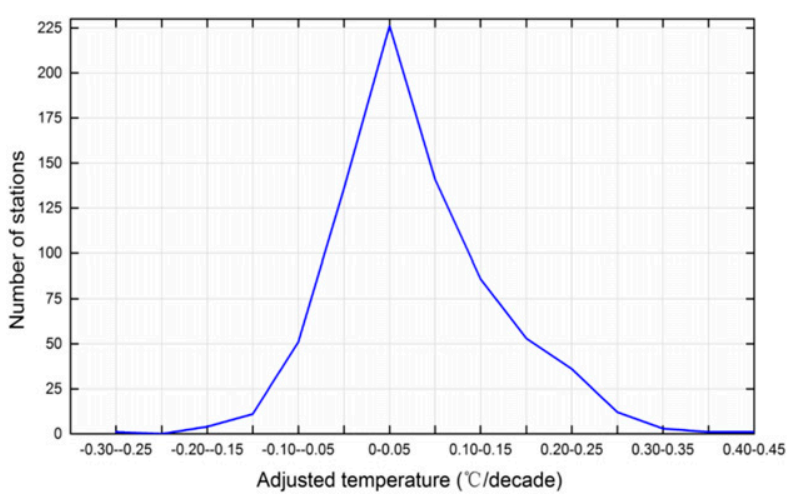

FIG. 3. Variations for number of stations with different adjusted temperature magnitude. 
1961-2015. We defined the spring as March to May, summer as June to August, autumn as September to November, and winter as last year's December and the current year's January and February. The regionaveraged annual and seasonal mean SAT anomalies for mainland China and six subregions were analyzed, and the spatial patterns of linear trends for annual- and seasonal-mean SAT were examined. We focused on the long-term trends of annual- and seasonal-mean SAT for each of the subregions and mainland China on a whole.

The six subregions were divided based on a comprehensive judgment of the spatial differences of natural geography, climate condition, and convenience of usage (Xu et al. 2011; Zhang et al. 2010), referring to previous works (Xu et al. 2011; Zhang et al. 2010). They are Northeast China (NEC), North China (NC), Northwest China (NWC), Southwest China (SWC), the middle to lower Yangtze River valley (YR), and South China (SC), respectively (Fig. 1c).

The methods to construct the regional average SAT anomaly series were as follows:

1) First, calculate the monthly, seasonal, and annual temperature anomalies of each year for each of the stations, which were the departures from the normal climate period from 1971 to 2000.

2) To calculate the grid average monthly, seasonal, and annual anomalies of each year for all the $2.5^{\circ} \times 2.5^{\circ}$ latitude and longitude grids over mainland China, simply arithmetically average all records of the stations within each of the grids (Figs. 1a,b).

3) Finally, to obtain the regional averaged monthly, seasonal, and annual mean SAT anomalies series over mainland China, calculate the average values of all grids by using the grids area weighting method (Jones and Hulme 1996). The formula for calculating the area weighted average of all grids is [Eq. (4)] is

$$
Y_{k}=\frac{\sum_{i=1}^{m}\left(\cos \theta_{i}\right) \times Y_{i k}}{\sum_{i=1}^{m}\left(\cos \theta_{i}\right)},
$$

where $Y_{k}$ means the regional average of year $k, i=1$, $2, \ldots, m$ ( $m$ is the number of grids), $Y_{i k}$ means the average of grid $i$ for year $k$, and $\theta_{i}$ means the center latitude of grid $i$.

The spatial distributions of the linear trends for annual and four seasons mean SAT over mainland China were analyzed by drawing isopleth of the trend values. The significance of the linear trend of temperature was examined by using correlation coefficient test method,

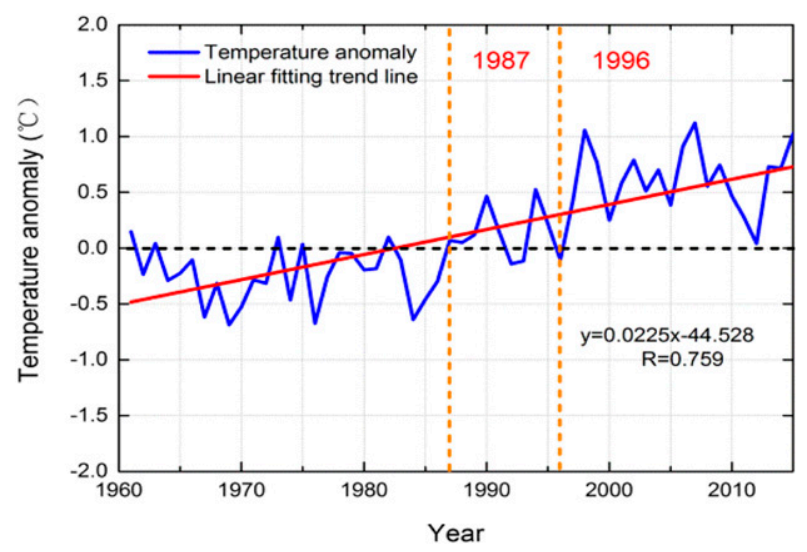

FIG. 4. Annual mean SAT anomalies in mainland China during 1961-2015.

with a trend considered to be statistically significant when $\alpha<0.05$.

Temperature trends were examined for statistical significance using the two-tailed Student's $t$ test. A trend is considered statistically significant if it is significant at the $95 \%(p<0.05)$ confidence level. The possible influence of serial correlation on trend estimate was not considered because the data series are long enough (Bayazit and Önöz 2007).

\section{Results}

\section{a. Time series of SAT anomalies}

Figure 4 shows the variation of annual mean SAT anomaly during 1961-2015 for mainland China. Annualmean SAT increased at a rate of $0.23^{\circ} \mathrm{C}$ decade $^{-1}$, and the trend is statistically significant $(p<0.05)$. The lowest annual-mean SAT anomaly was $-0.69^{\circ} \mathrm{C}$ in 1969 . The anomalies before 1987 were mostly negative, with positive temperature anomalies only in 1961, 1963, 1973, 1975, and 1982; since 1987, however, the temperature has risen sharply, reaching the highest positive anomaly of $1.12^{\circ} \mathrm{C}$ in 2007 . There were 26 years with positive temperature anomalies after 1987 . The difference of annual mean SAT between the first 5 years in the 1960s and the last 5 years studied (2011-15) reached $0.67^{\circ} \mathrm{C}$. The first decade of the twenty-first century was the warmest decade, and 2007 was the warmest year, in mainland China over the past 55 years.

The seasonal mean SAT anomalies all showed the rising trends in mainland China over the past 55 years, but the warming rates were different (Fig. 5). In the period analyzed, the winter, autumn, spring, and summer mean SAT rose by $1.56^{\circ}, 1.28^{\circ}, 1.24^{\circ}$, and $0.84^{\circ} \mathrm{C}$ respectively. Therefore, the rising rate of winter mean SAT was $0.28^{\circ} \mathrm{C}$ decade $^{-1}$, which was the largest among the four 

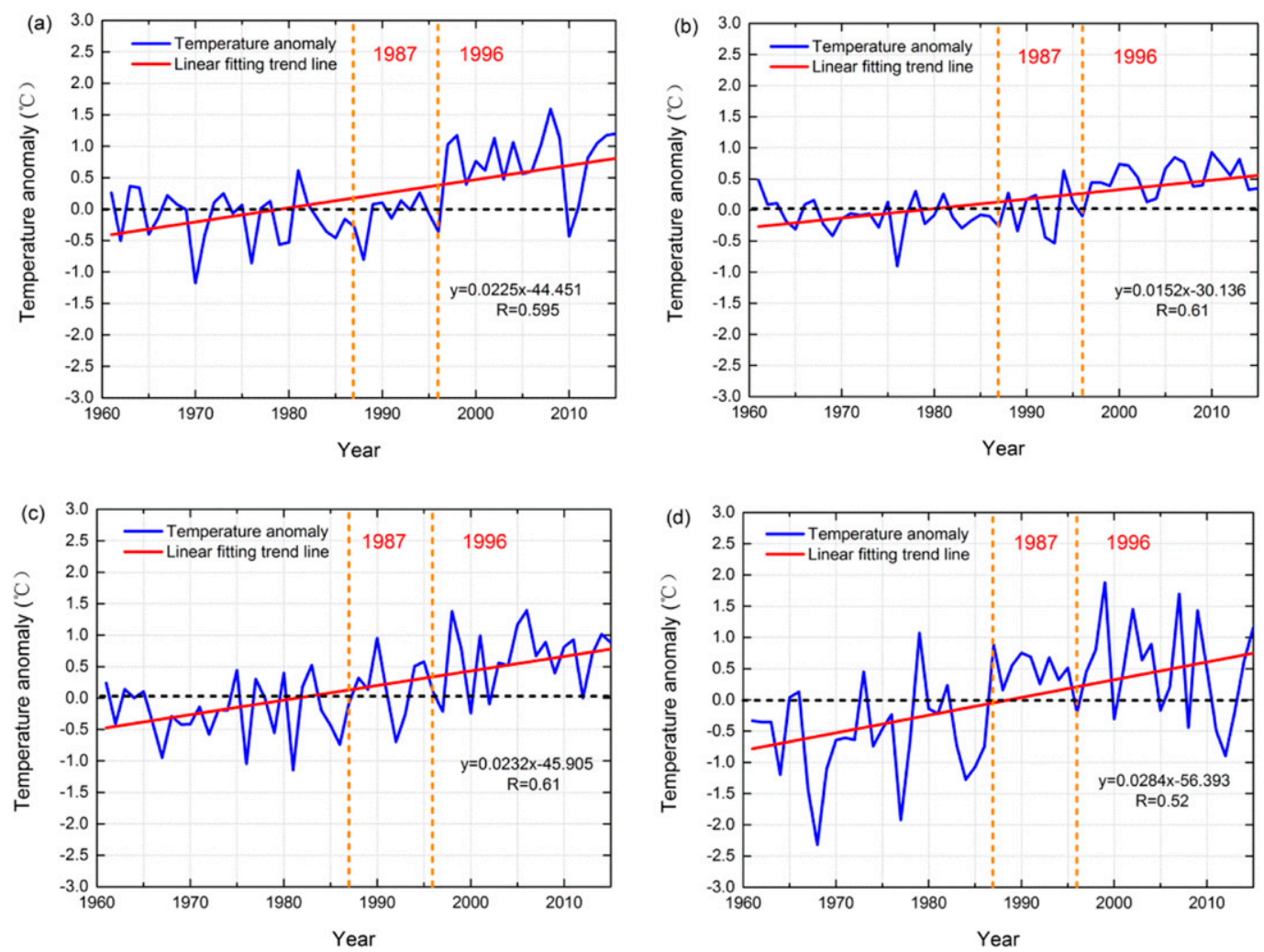

FIG. 5. Seasonal mean SAT anomalies in mainland China during 1961-2015: (a) spring, (b) summer, (c) autumn, and (d) winter.

seasons, and autumn, spring, and summer mean warming rates were $0.23^{\circ}, 0.23^{\circ}$, and $0.15^{\circ} \mathrm{C}$ decade ${ }^{-1}$, respectively.

The spring mean SAT was the lowest in 1970, with a negative anomaly of $-1.17^{\circ} \mathrm{C}$, and it reached a peak in 2008. The summer mean SAT showed the lowest value in 1976 and a peak in 2010. The warmest autumn occurred in 2006 , with an anomaly of $1.40^{\circ} \mathrm{C}$, and the coldest autumn was in 1981 , with an anomaly of $-1.15^{\circ} \mathrm{C}$. The lowest winter mean SAT was found in 1968 , and the anomaly was as low as $-2.32^{\circ} \mathrm{C}$. The highest winter mean SAT, $1.88^{\circ} \mathrm{C}$ higher than normal, appeared in 1999.

For spring, summer, and autumn, the fluctuation ranges and linear trends of seasonal mean temperature were generally small, and the most stable temperatures occurred after about the mid-1990s. Spring and summer mean temperature began to increase in the mid- to late 1990s, much later than for autumn and winter, which witnessed obvious warming in the mid-1980s. Winter mean temperature also saw a greater interannual and decadal variability than any other season.

\section{b. Monthly mean trends and decadal variations}

Figure 6 presents the monthly mean SAT trends in mainland China over 1961-2015. The fastest warming occurred in February at a rate of $0.48^{\circ} \mathrm{C}$ decade ${ }^{-1}$. March, November, and April also registered higher trends of $0.28^{\circ}, 0.27^{\circ}$, and $0.24^{\circ} \mathrm{C}$ decade $^{-1}$. Smaller warming trends of $0.14^{\circ}$ and $0.15^{\circ} \mathrm{C}$ decade $^{-1}$ appeared in July and May, and the smallest warming occurred in

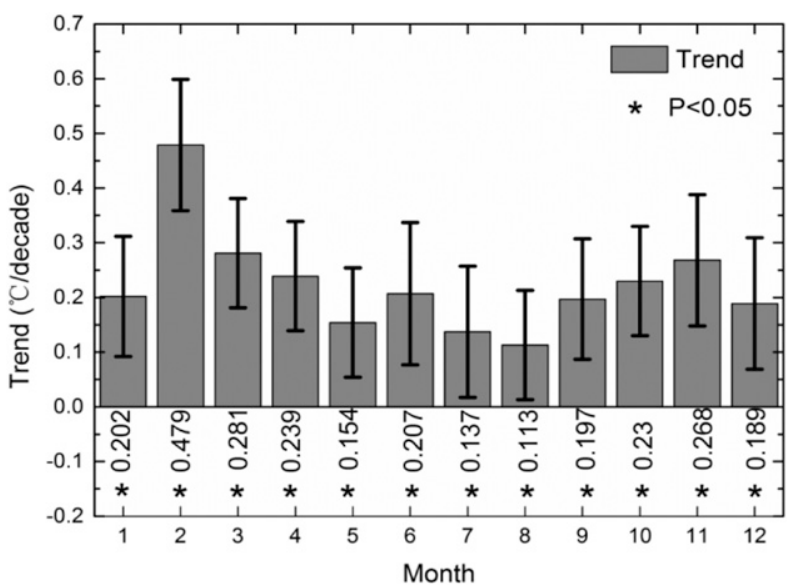

FIG. 6. Trends of monthly mean SAT in mainland China during 1961-2015. Numbers indicate the rates of change. Error bars indicate 2 times the standard deviation. Statistically significant $(p<$ $0.05)$ trends are marked with asterisks. 


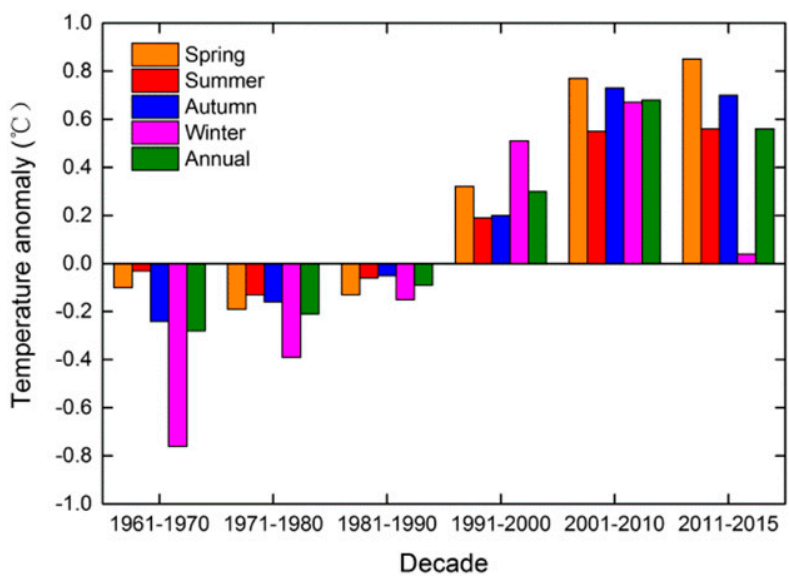

FIG. 7. Decadal averages of annual and seasonal mean SAT anomalies in mainland China.

August at a rate of $0.11^{\circ} \mathrm{C}$ decade ${ }^{-1}$. The trends of all months were statistically significant at the $95 \%$ confidence level. The monthly results are consistent with the seasonal features in mainland China obtained in this paper.

As can be seen from Fig. 7, the spring mean SAT in mainland China decreased before the 1970s, and gradually increased from the 1980s. The lowest temperature occurred in the 1970 s with $-0.19^{\circ} \mathrm{C}$. The summer mean SAT decreased slightly before the 1970s and then increased generally after the 1970s. The autumn mean SAT got warm gradually from the 1960s onward. For the winter mean SAT, it warmed gradually before the beginning of the twenty-first century, and got slightly colder in the last 5 years. The annual mean SAT showed a warming trend before the beginning of the twenty-first century and a cooling trend afterward, and it was colder than normal between the 1960s and 1980s, with decadal mean temperature anomalies of $-0.28^{\circ},-0.21^{\circ}$, and $-0.09^{\circ} \mathrm{C}$ respectively.

\section{c. Time series of regional average temperature}

The SAT trends for six climate regions and mainland China during 1961-2015 are given in Table 2. In general, the annual mean SATs of the regions all showed warming trends. The lowest increasing trend appeared in the Yangtze River region with a trend of $0.14^{\circ} \mathrm{C} \mathrm{decade}{ }^{-1}$, and higher warming trends appeared in Northwest, Northeast, Southwest, and North China, with the increasing trends of $0.29^{\circ}, 0.27^{\circ}, 0.22^{\circ}$, and $0.21^{\circ} \mathrm{C}_{\text {decade }}^{-1}$, respectively.

Seasonal mean SAT also exhibited the warming trends in each of the regions except for summer of the Yangtze River. The lowest spring warming was seen in South China. For summer, the Yangtze River showed a weak cooling with the trend of $-0.01^{\circ} \mathrm{C}$ decade $^{-1}$, but Northwest, Northeast, and Southwest China experienced
TABLE 2. Trends of annual and seasonal mean SAT for six climate regions in mainland China during 1961-2015 (unit: ${ }^{\circ} \mathrm{C}$ decade $\left.^{-1}\right)$. NEC, NC, NWC, SWC, YR, and SC represent Northeast China, North China, Northwest China, Southwest China, the middle to lower Yangtze River valley, and South China respectively. An asterisk denotes that the trend is statistically significant at the $0.05(p<0.05)$ level.

\begin{tabular}{lccccc}
\hline \hline \multirow{2}{*}{ Region } & \multicolumn{5}{c}{ Temperature trend } \\
\cline { 2 - 6 } & Annual & Spring & Summer & Autumn & Winter \\
\hline Mainland China & $0.23^{*}$ & $0.23^{*}$ & $0.15^{*}$ & $0.23^{*}$ & $0.28^{*}$ \\
NEC & $0.27^{*}$ & $0.26^{*}$ & $0.22^{*}$ & $0.28^{*}$ & $0.32^{*}$ \\
NC & $0.21^{*}$ & $0.26^{*}$ & $0.09^{*}$ & $0.18^{*}$ & $0.29^{*}$ \\
NWC & $0.29^{*}$ & $0.26^{*}$ & $0.24^{*}$ & $0.33^{*}$ & $0.33^{*}$ \\
SWC & $0.22^{*}$ & $0.18^{*}$ & $0.18^{*}$ & $0.22^{*}$ & $0.30^{*}$ \\
YR & $0.14^{*}$ & $0.22^{*}$ & -0.01 & $0.15^{*}$ & $0.20^{*}$ \\
SC & $0.16^{*}$ & $0.15^{*}$ & $0.11^{*}$ & $0.19^{*}$ & $0.20^{*}$ \\
\hline
\end{tabular}

significant warming. The lowest autumn mean SAT increase occurred in the Yangtze River, and the highest autumn increasing trend occurred in Northwest China. For winter, the smallest warming was seen in the Yangtze River and South China, and the largest warming appeared in Northwest China, but all the regions except Yangtze River witnessed the largest increases in SAT among all of the seasons. In summary, the warming was the largest in winter, and the regions of Southwest, Northwest, North, and Northeast China all showed larger and significant warming in four seasons. Annual and seasonal mean SAT trends of each region were significant except for summer of the Yangtze River.

The SAT anomalies variations for each of the climate regions are presented in Fig. 8. The larger warming was in Northeast, North, Northwest, and Southwest China. Northwest China had little change before the mid-1980s but a tremendous warming after the mid-1980s. An obvious fluctuation was found in Northeast China in the past 55 years, with a slight cooling trend in 1960 s, and a fast warming after the mid-1980s. The other regions showed variations similar to Northwest and Northeast China, with the warming trends not so obvious before the mid-1980s, but a rapid warming since then.

\section{d. Spatial characteristics of temperature change}

Figure 9 exhibits the spatial distribution of trends for annual mean SAT during 1961-2015 in mainland China. In the 55 years, annual-mean SAT increased at a rate of $0.30^{\circ}-0.40^{\circ} \mathrm{C}$ decade $^{-1}$ in regions of northern and central Northeast China, northern North China, eastern, northern, and southwestern Northwest China, and northern Southwest China. Annual mean SAT rose at a rate of $0.20^{\circ}-0.30^{\circ} \mathrm{C}$ decade $^{-1}$ in southern, eastern, and midnorthern Northeast China, midnorthern and southeastern North China, the eastern Yangtze River basin, 

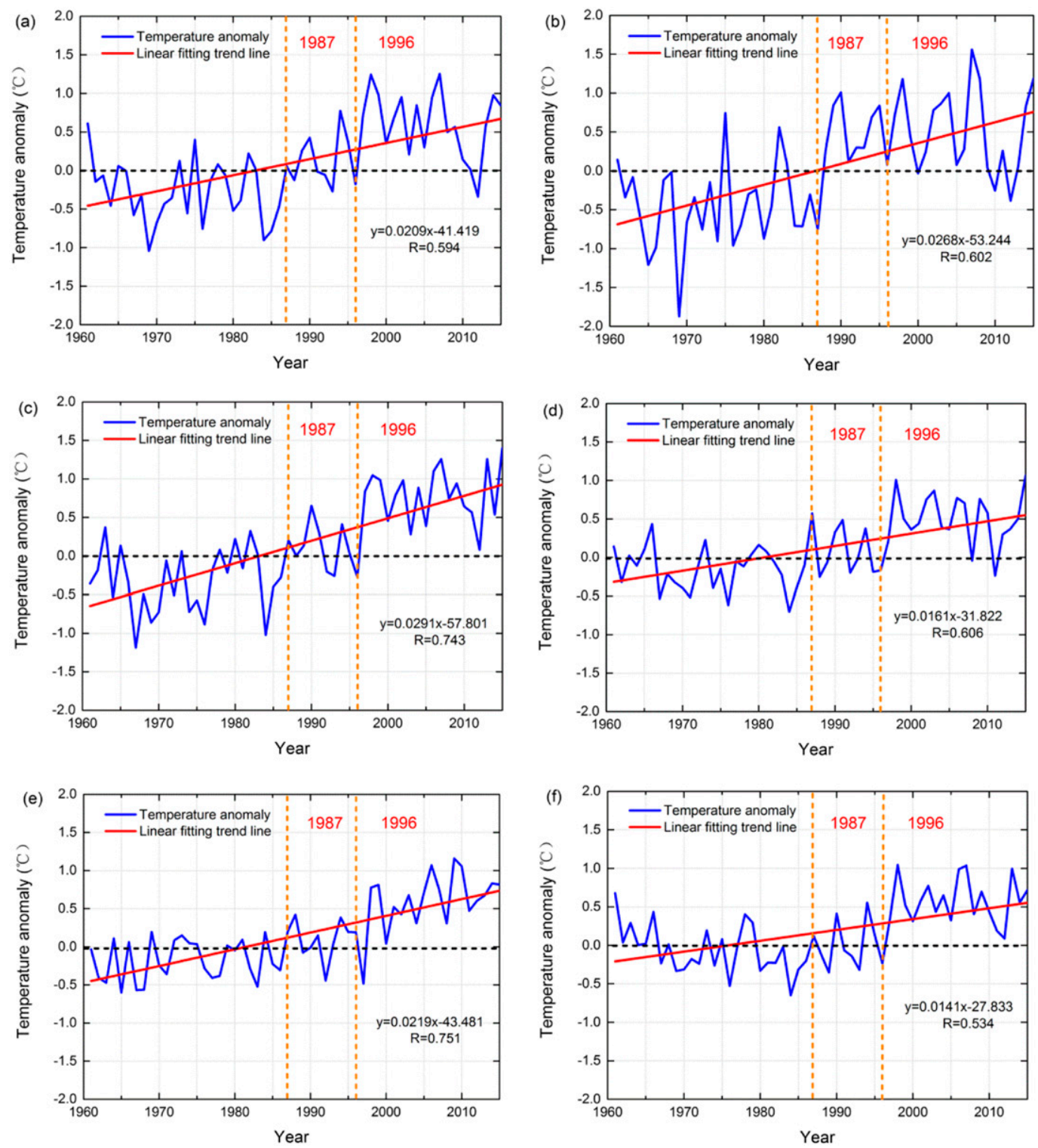

FIG. 8. Regional average annual mean SAT anomalies during 1961-2015: (a) North China, (b) Northeast China,

(c) Northwest China, (d) South China, (e) Southwest China, and (f) the middle to lower Yangtze River valley.

and central Southwest and Northwest China. The weakest warming appeared in central parts of mainland China, including a little part of southwestern North China, the northwestern Yangtze River, and the eastern part of the Southwest China.

The spatial patterns of seasonal mean SAT trends in mainland China are shown in Fig. 10. The most obvious characteristic is the contrast of the remarkable winter warming and the weaker summer temperature trends, with the summer mean SAT even decreasing in northern parts of the Yangtze River region and southern North China in the 55 years. Spring mean SAT also slightly increased at a rate up to $0.20^{\circ} \mathrm{C}$ decade $^{-1}$ in most parts of South China, the western and southern Yangtze River basin, eastern Southwest China, central North China, southern Northeast China, and a little part of central Northwest China. Large increases in spring mean SAT were found in western Northeast China, a small part of northern and southeastern North China, the northeastern Yangtze River region, and a small part of northeastern Northwest China, with a rate of $0.30^{\circ}-0.40^{\circ} \mathrm{C}$ decade $^{-1}$.

Summer mean SAT increased at a smaller rate of $0^{\circ}-0.20^{\circ} \mathrm{C}$ decade $^{-1}$ in South China, the eastern and 


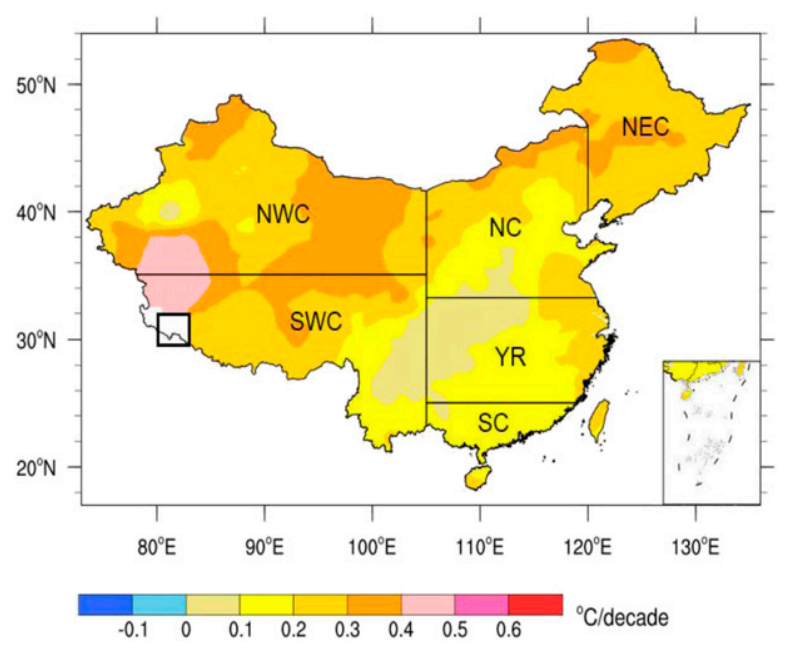

FIG. 9. Trends of annual mean SAT in mainland China during 1961-2015. A black box represents lack of data.

southwestern Yangtze River region, eastern Southwest China, central and southeastern North China, and part of central Northwest China. A remarkable increase in summer mean SAT was observed in most of Northwest, Southwest, Northeast, and northern North China with a rate at least $0.20^{\circ} \mathrm{C}$ decade $^{-1}$. A decrease of summer mean SAT appeared in the central, western, and northern Yangtze River basin and in central and southwestern North China.

In most parts of the upper and middle Yangtze River basin, western and central South China, parts of eastern Southwest China, and most of North China, autumn mean SAT increased at a rate of $0^{\circ}-0.20^{\circ} \mathrm{C}$ decade $^{-1}$, registering the smallest warming in the country. The larger and significant increase in autumn mean SAT appeared in southeastern, southwestern, and northern Northwest China and in central Northeast China, ranging from $0.30^{\circ}$ to $0.40^{\circ} \mathrm{C}$ decade $^{-1}$. The largest increase in autumn mean SAT occurred in western Southwest China and a little part of southwestern and northwestern Northwest China with a rate at least $0.40^{\circ} \mathrm{C}$ decade $^{-1}$.

Winter witnessed the largest increase in seasonal mean SAT. The most significant increase appeared in a belt extending from the northernmost part of Northeast China to the southernmost part of Southwest China, showing large trends of $0.40^{\circ}-0.50^{\circ} \mathrm{C}$ decade $^{-1}$. In most other regions, the winter mean SAT trends of $0^{\circ}$ $0.40^{\circ} \mathrm{C}$ decade $^{-1}$ could be observed, with the smallest warming in parts of western Yangtze River, southeastern Southwest China, and western South China.

\section{Discussion}

This work made a first attempt to analyze the SAT change over mainland China by using the urbanization-bias
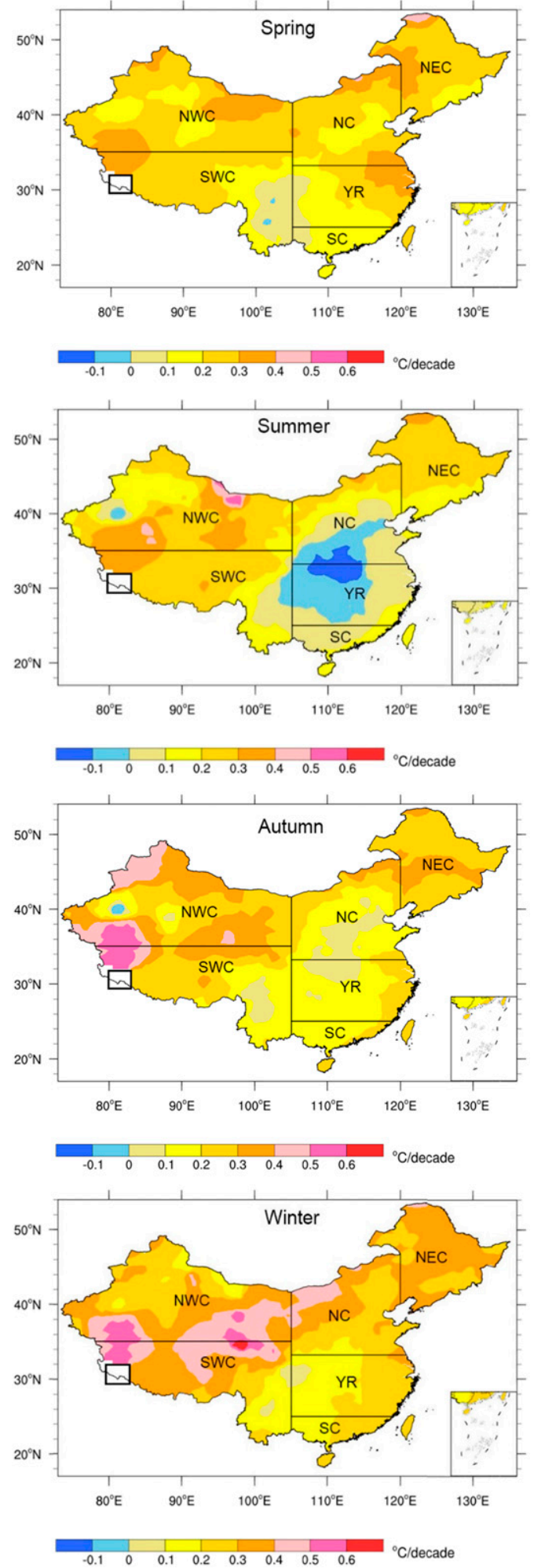

FIG. 10. Trends of seasonal mean SAT in mainland China during 1961-2015. A black box represents lack of data. 

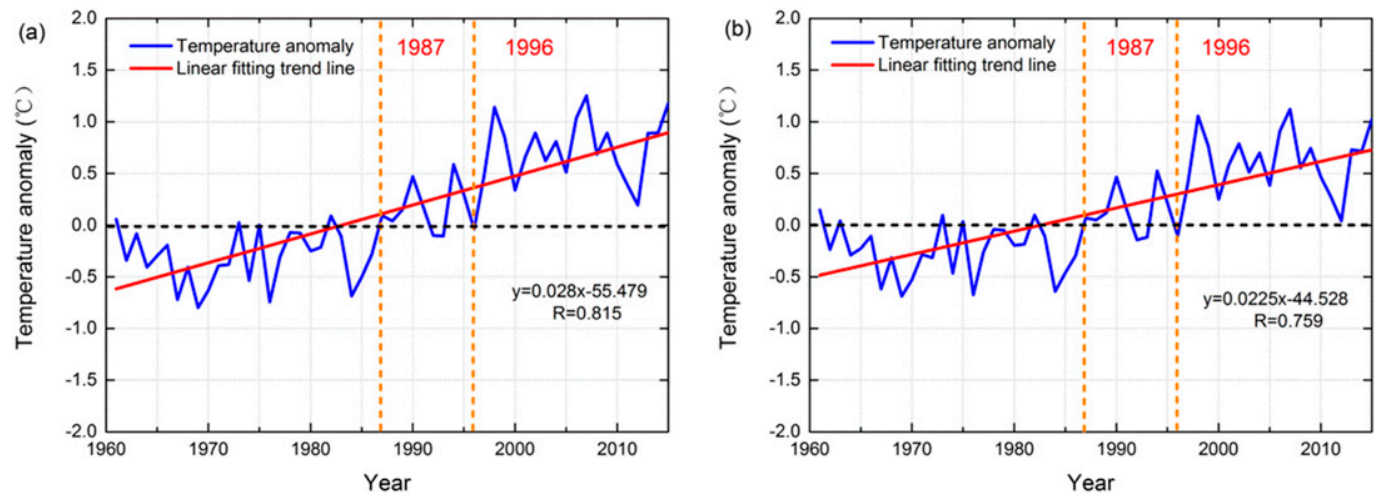

FIG. 11. Country averaged annual mean SAT anomalies (a) before and (b) after urbanization bias adjustment in mainland China during 1961-2015.

adjusted dataset. From the annual mean SAT anomaly curves for the before and after adjustment data (Fig. 11), two obvious characteristics could be found: 1) the trend after adjustment was reduced compared to that before adjustment, and 2) the annual mean SAT anomaly curve became more flattened in years after 1998.

The period after 1998 is referred to as the warming hiatus, or slowdown of climate warming (Trenberth and Fasullo 2013; Sun et al. 2017a,b). There is a weak upward trend before data adjustment during the period in mainland China, but the trend is almost 0 after the urbanization bias was corrected. For the whole period analyzed, the urbanization bias had caused an overestimate of the annual warming rate of more than $19.6 \%$, a little smaller than, but close to, the contribution of $27.3 \%$ estimated in Zhang et al. (2010) for the period 1961-2004 using the same homogenized data of the national stations. In this study, when considering the period 1961-2013, the warming trend of SAT in mainland China is $0.22^{\circ} \mathrm{C}$ decade $^{-1}$, and the SAT increase for the whole period is $1.16^{\circ} \mathrm{C}$. This is a little higher than the deurbanized value of $0.95^{\circ} \mathrm{C}$ (over all warming $1.44^{\circ} \mathrm{C}$ ) during the period $1961-2013$ reported in Sun et al. (2016). For period 1961-2010 in this study, the warming trend of SAT in mainland China is $0.24^{\circ} \mathrm{C}$ decade $^{-1}$, and the SAT increased by $1.19^{\circ} \mathrm{C}$ for the 50 years, which is close to the warming of $1.09^{\circ} \mathrm{C}$ observed in global mean land SAT over the period 1951-2010. The higher warming rate in this study may be because the estimate in Sun et al. (2016) used a dataset of a larger observational station network that included more rural stations, and also the urbanization contribution as given by them were larger than that estimated in this paper.

By applying a homogenized daily SAT dataset of the national stations, Ren et al. (2015) found that annual mean SAT increased at rates of $0.31^{\circ} \mathrm{C}$ decade ${ }^{-1}$ in mainland China during 1961-2008, when the data were not corrected for urbanization bias, but this was reduced to $0.24^{\circ} \mathrm{C}$ decade ${ }^{-1}$ if a correction was applied to the country-averaged SAT data series. The increasing trend of annual mean SAT reduced by $22.6 \%$ after the data series were adjusted. This is very close to the 19.6\% urbanization bias obtained for period 1961-2015 in this paper.

In an earlier study, Ren et al. (2005a) used a monthly mean temperature dataset, which had been adjusted for inhomogeneity, to analyze SAT change during 19512001 in mainland China. Here we made a comparison of the present work with the previous analysis, by ending the urbanization-bias adjusted data in 2001. In Ren et al. (2005a), there were only two warm years before the mid1980s (1973 and 1982) but 13 warm years after the mid1980s, and the warmest year occurred in 1998 with a country average annual mean temperature anomaly of $1.13^{\circ} \mathrm{C}$. When we used the adjustment data, more warm years ( 6 years) were found before 1987, but the number of warm years after 1987 was reduced to 12 , and the annual mean SAT anomaly of the warmest year in 1998 was now $1.06^{\circ} \mathrm{C}$.

Winter has been the season that has experienced the most rapid warming in mainland China. After the mid1980 s, there were 14 warm winters, and the maximum anomaly was $1.93^{\circ} \mathrm{C}$ in 1999 , when the data without adjustment of the urbanization bias were applied (Ren et al. 2005a). After the urbanization bias adjustment, there were 13 warm winters, with the maximum anomaly in 1999 reduced to $1.88^{\circ} \mathrm{C}$.

The spatial patterns of the annual and seasonal mean SAT trends also exhibited obvious differences from those of the previous analyses. The largest contrast was an increased extent of the weak warming area appearing in central parts of mainland China, which included the 
southwestern part of North China, the western part of the Yangtze River region, and the eastern part of Southwest China. The weak warming of the Sichuan basin and its neighboring regions may have been related to the combined influence of landform and pollutants emission. The regions are located to the east of the Tibetan Plateau, and the near-surface wind speed is very small when the westerly in mid- and lower troposphere bypass the Tibetan Plateau, forming one static wind area, which make the aerosols not easy to spread. Hence, the annual mean SAT in the regions increased weakly or even decreased at a few stations. However, the weak warming area presently extended to include the southern part of the Loess Plateau and the southwestern part of the North China Plain, and this may have been caused by the larger adjustments of the urbanization biases due to the more apparently unrepresentative observational settings in the flat regions.

In eastern part of Southwest China, the annual mean SAT showed a weak increasing trend, which is different from previous studies that reported a decreasing trend, despite that the cooling was not significant (Zhang and Fang 1988; Song 1994; Chen et al. 1991; Ren et al. 2005b). This may due to the warming trend after the mid-1990s in this region (Ren et al. 2005b) and the data series were extended to 2015 in this paper to catch the warming stage well.

Compared to the results of the only homogenized data (Ren et al. 2005b), the warming trends of annual mean SAT in Northeast China and North China obviously decreased, which caused a relatively more significant cooling in Northeast China after 1998 under the background of the global warming slowdown. Both the global warming hiatus after 1998 and the urbanization bias adjustment are important for the difference. The region is a relatively more significant cooling area in the Northern Hemisphere after 1998 (Sun et al. 2017a), and the urbanization effect on the SAT trends is generally larger (Zhang et al. 2010). Therefore, the urbanization-bias adjusted data series showed less warming during the 55 years.

In the middle and lower reaches of the Yangtze River and the Huaihe River basin, summer mean SAT showed a weak decreased trend (Ren et al. 2005b); after the adjustment, the weak cooling area extended to southwestern and central North China region. The southwestern North China region is located in the Qinling Mountains and the Loess Plateau, and the weak cooling may have been caused mainly by the rugged terrain, which resulted in a less development and urbanization bias; also, the urbanization effects in the central part of North China region were stronger, with the summer mean SAT trends shifting from positive to negative after the adjusted data were used.

In the western part of Southwest China, both national stations and reference stations were lacking. Actually there is only one reference station (Shiquanhe station) in the area, and it is also located in a small town, which may have been affected itself by urbanization. Therefore, the robustness of the adjustment in this area might be lower, and further work is needed when more data are available.

Using the urbanization-bias adjusted monthly mean SAT dataset of 763 RCBMS to analyze the long-term SAT change, a more real spatial and temporal pattern could be obtained, with the overestimated warming bias in the country on a whole reduced to a large extent and the more coherent spatial characteristics of the SAT change obtained. The new urbanization bias adjusted monthly mean SAT dataset could be applied in monitoring, detection, and attribution of large-scale climate change. There will also be some practical value in areas including climate model validation, impact assessments, and vulnerability studies of regional climate change.

However, there are still some issues that need to be solved in the studies of SAT change in mainland China. One major issue would be related to the representativeness of the reference stations when urbanization bias is assessed and corrected. The reference stations, as a baseline to adjust urbanization bias, are actually not located in real rural areas, and they are being increasingly affected by urbanization processes in the small cities and towns in the country. Considering this deficiency, the adjustments made in this work have to be regarded as conservative, and there are still residual biases of the urbanization effect in the adjusted temperature data series. It is also noteworthy that the absence of observational data in vast regions of the Qinghai-Tibetan Plateau and the Taklimakan Desert may have brought considerable uncertainty to estimates of long-term SAT changes and the adjustment of urbanization biases in western China. These should be gradually solved in future work.

\section{Conclusions}

In this paper, the SAT changes in mainland China during 1961-2015 were analyzed by using the urbanizationbias adjusted dataset of 763 national stations. The following conclusions can be drawn:

1) Annual mean SAT increased significantly at a rate of $0.23^{\circ} \mathrm{C}$ decade $^{-1}$ in mainland China. The rising rate of winter mean SAT reached $0.28^{\circ} \mathrm{C}$ decade $^{-1}$, and the autumn, spring, and summer mean warming rates were $0.23^{\circ}, 0.23^{\circ}$, and $0.15^{\circ} \mathrm{C}$ decade $^{-1}$ respectively.

2) The annual mean SAT values in different regions all showed significant increasing trends. The smallest warming appeared in the Yangtze River region, 
with a rate of $0.14^{\circ} \mathrm{C}$ decade ${ }^{-1}$, and the largest warming appeared in Northwest China, reaching $0.29^{\circ} \mathrm{C}_{\text {decade }^{-1}}$. Summer mean SAT in the Yangtze River region exhibited a weak cooling trend.

3) The fastest warming occurred in February at a rate of $0.48^{\circ} \mathrm{C}$ decade $^{-1}$, followed by March, November, and April $\left(0.28^{\circ}, 0.27^{\circ}\right.$, and $0.24^{\circ} \mathrm{C}$ decade $^{-1}$ respectively). July and May witnessed slower warming trends $\left(0.14^{\circ}\right.$ and $0.15^{\circ} \mathrm{C}$ decade $\left.{ }^{-1}\right)$, and the slowest warming occurred in August $\left(0.11^{\circ} \mathrm{C}\right.$ decade $\left.^{-1}\right)$.

4) For annual mean SAT, weaker warming areas with rends of $0^{\circ}-0.10^{\circ} \mathrm{C}$ decade $^{-1}$ appeared in central parts of mainland China. Parts of the weaker warming areas, including southern North China, a little part of eastern Southwest China, and the northwestern Yangtze River region, were characterized by a cooling in summer.

Acknowledgments. This work was supported by the Chinese Ministry of Science and Technology (MOST) National Key Research and Development Program (Fund 2018YFA0605603) and the Natural Science Foundation of China (NSFC) (Fund 41575003).

\section{REFERENCES}

Bayazit, M., and B. Önöz, 2007: To prewhiten or not to prewhiten in trend analysis. Hydrol. Sci. J., 52, 611-624, https://doi.org/ 10.1623/hysj.52.4.611.

Cao, L. J., Y. N. Zhu, G. L. Tang, Y. Yuan, and Z. W. Yan, 2016: Climatic warming in China according to a homogenized data set from 2419 stations. Int. J. Climatol., 36, 4384-4392, https:// doi.org/10.1002/joc.4639.

Chen, L. X., and W. Q. Zhu, 1998: Study on climate change of China over the past 45 years. Acta Meteor. Sin., 56, 257-271.

—, Y. N. Shao, Q. F. Zhang, Z. H. Ren, and G. S. Tian, 1991: Preliminary analysis of climatic change during the last 39 years in China (in Chinese). J. Appl. Meteor. Sci., 2, 164-174.

Ding, Y. H., and G. Y. Ren, 2008: Introduction to Climate Change Science of China (in Chinese). China Meteorological Press, 281 pp.

He, Y. T., G. S. Jia, Y. H. Hu, and Z. J. Zhou, 2013: Detecting urban warming signals in climate records. Adv. Atmos. Sci., 30,11431153, https://doi.org/10.1007/s00376-012-2135-3.

Hua, L. J., Z. G. Ma, and W. D. Guo, 2008: The impact of urbanization on air temperature across China. Theor. Appl. Climatol., 93, 179-194, https://doi.org/10.1007/s00704-007-0339-8.

Huang, M., G. B. Peng, L. M. Leslie, X. M. Shao, and W. Y. Sha, 2005: Seasonal and regional temperature changes in China over the 50 year period 1951-2000. Meteor. Atmos. Phys., 89, 105-115, https://doi.org/10.1007/s00703-005-0124-0.

Jiang, Z. H., Q. Huang, and Q. X. Li, 2008: Study of precipitation series homogeneous adjustment and their correction over China in the last 50 years (in Chinese). Climatic Environ. Res., 13, 67-74.

Jones P. D., and M. Hulme, 1996: Calculating regional climatic time series for temperature and precipitation: Methods and illustrations. Int. J. Climatol., 16, 361-377, https://doi.org/10.1002/ (SICI)1097-0088(199604)16:4<361::AID-JOC53>3.0.CO;2-F.
Karl, T. R., and C. N. Williams, 1987: An approach to adjusting climatological time series for discontinuous inhomogeneities. J. Climate Appl. Meteor., 26, 1744-1763, https://doi.org/ 10.1175/1520-0450(1987)026<1744:AATACT>2.0.CO;2.

Li, Q. X., 2011: Introductory Study of Historic Climate Data Homogeneity. China Meteorological Press, 115 pp.

— and Coauthors, 2015: China experiencing the recent warming hiatus. Geophys. Res. Lett., 42, 889-898, https://doi.org/ 10.1002/2014GL062773.

Lin, X. C., S. Q. Yu, and G. L. Tang, 1995: Temperature series of the past 100 years for China (in Chinese). Atmos. Sci. 19, 525-534.

Mitchell, T. D., and P. D. Jones, 2005: An improved method of constructing a database of monthly climate observations and associated high-resolution grids. Int. J. Climatol., 25, 693-712, https://doi.org/10.1002/joc.1181.

Qian, W. H., and X. Lin, 2004: Regional trends in recent temperature indices in China. Climate Res., 27, 119-134, https://doi.org/ $10.3354 / \mathrm{cr} 027119$.

_ - and A. Qin, 2005: Spatial-temporal characteristics of temperature variation in China. Meteor. Atmos. Phys., 93, 1-16, https://doi.org/10.1007/s00703-005-0163-6.

Qiao, S. X., and J. Qin, 1990: The diagnoses of the effect from the urbanization of a county town on temperature (in Chinese). Meteor. Mon., 16, 17-20, https://doi.org/10.7519/j.issn.10000526.1990.11.003.

Ren, G. Y., and Y. Q. Zhou, 2014: Urbanization effect on trends of extreme temperature indices of national stations over mainland China, 1961-2008. J. Climate, 27, 2340-2360, https:// doi.org/10.1175/JCLI-D-13-00393.1.

_ J. Guo, M. Z. Xu, Z. Y. Chu, L. Zhang, X. K. Zou, Q. X. Li, and X. N. Liu, 2005a: Climate changes of China's mainland over the past half century (in Chinese). Acta Meteor. Sin., 63, 942-956.

—, M. Z. Xu, Z. Y. Chu, J. Guo, Q. X. Li, X. N. Liu, and Y. Wang, 2005b: Changes of surface air temperature in China during 1951-2004 (in Chinese). Climatic Environ. Res., 10, 717-727.

— gional temperature changes in China (in Chinese). Climatic Environ. Res., 10, 701-716.

- Y. Q. Zhou, Z. Y. Chu, J. X. Zhou, A. Y. Zhang, J. Guo, and X. F. Liu, 2008: Urbanization effects on observed surface air temperature trends in North China. J. Climate, 21, 1333-1348, https://doi.org/10.1175/2007JCLI1348.1.

—, A. Y. Zhang, Z. Y. Chu, J. X. Zhou, Y. Y. Ren, and Y. Q. Zhou, 2010: Principles and procedure for selecting reference surface air temperature stations in China (in Chinese). Meteor. Sci. Technol., 38, 78-85.

— Y. Y. H. Ding, Z. C. Zhao, J. Y. Zheng, T. W. Wu, G. L. Tang, and Y. Xu, 2012: Recent progress in studies of climate change in China. Adv. Atmos. Sci., 29, 958-977, https://doi.org/ 10.1007/s00376-012-1200-2.

- , and Coauthors, 2015: An integrated procedure to determine a reference station network for evaluating and adjusting urban bias in surface air temperature data. J. Appl. Meteor. Climatol., 54, 1248-1266, https://doi.org/10.1175/ JAMC-D-14-0295.1.

Ren, Y. Y., D. Parker, G. Y. Ren, and R. Dunn, 2016: Tempospatial characteristics of sub-daily temperature trends in mainland China. Climate Dyn., 46, 2737-2748, https://doi.org/ 10.1007/s00382-015-2726-7.

Song, L. C., 1994: Characteristics of temperature in spatial and temporal variation in China during recent 40 years (in Chinese). J. Appl. Meteor. Sci., 5, 119-124. 
Sun, X. B., G. Y. Ren, Y. Y. Ren, Y. H. Fang, Y. L. Liu, X. Y. Xue, and P. F. Zhang, 2017a: A remarkable climate warming hiatus over Northeast China since 1998. Theor. Appl. Climatol., 133, 579-594, https://doi.org/10.1007/s00704-017-2205-7.

, - - W. H. Xu, Q. Li, and Y. Ren, 2017b: Global landsurface air temperature change based on the new CMA GLSAT data set. Sci. Bull., 62, 236-238, https://doi.org/ 10.1016/j.scib.2017.01.017.

Sun, Y., X. B. Zhang, G. Y. Ren, F. W. Zwiers, and T. Hu, 2016: Contribution of urbanization to warming in China. Nat. Climate Change, 6, 706-709, https://doi.org/10.1038/nclimate2956.

Tang, G. L., G. Y. Ren, and J. X. Zhou, 2008: Change of urban heat island intensity and its effect on surface mean air temperature records in Southwest China (in Chinese). J. Appl. Meteor. Sci. 19, 722-730.

Tang, H. Y., P. M. Zhai, and Z. Y. Wang, 2005: On change in mean maximum temperature, minimum temperature, and diurnal range in China during 1951-2002 (in Chinese). Climatic Environ. Res., 10, 728-735.

Trenberth, K. E., and J. T. Fasullo, 2013: An apparent hiatus in global warming? Earth's Future, 1, 19-32, https://doi.org/ 10.1002/2013EF000165.

Wang, F., and Q. S. Ge, 2012: Estimation of urbanization bias in observed surface temperature change in China from 1980 to 2009 using satellite land-use data. Chin. Sci. Bull., 57, 17081715, https://doi.org/10.1007/s11434-012-4999-0.

Wang, Z. Y., Y. H. Ding, J. H. He, and J. Yu, 2004: An updated analysis of the climate change in China in recent 50 years (in Chinese). Acta Meteor. Sin., 62, 228-236, https://doi.org/10.11676/ qxxb2004.023.

Wen, K. M., G. Y. Ren, J. Li, Y. Y. Ren, X. B. Sun, and Y. Q. Zhou, 2019: Adjustment of urbanization bias in surface air temperature over mainland China (in Chinese). Adv. Geogr. Sci., in press.

Xu, X., Y. G. Du, J. P. Tang, and Y. Wang, 2011: Variations of temperature and precipitation extremes in recent two decades over China. Atmos. Res., 101, 143-154, https://doi.org/10.1016/ j.atmosres.2011.02.003.

Yang, X. C., Y. L. Hou, and B. D. Chen, 2011: Observed surface warming induced by urbanization in east China. J. Geophys. Res., 116, D14113, https://doi.org/10.1029/2010JD015452.

Yu, Y., J. Li, Z. H. Ren, and Coauthors, 2012: Application of standardized method in estimating missing daily mean air temperature (in Chinese). Meteor. Mon., 38, 1135-1139.

Zhai, P. M., and F. M. Ren, 1999: On changes of China's maximum and minimum temperature in 1951-1990. Acta Meteor. Sin., 13, 278-290.

Zhang, A. Y., 2009: Detection and correction of urbanization bias to national station data series of surface air temperature (in Chinese). M.S. thesis, Chinese Academy of Meteorological Sciences, $60 \mathrm{pp}$.

- , G. Y. Ren, J. X. Zhou, Z. Y. Chu, Y. Y. Ren, and G. L. Tang, 2010: Urbanization effect on surface air temperature trends over China (in Chinese). Acta Meteor. Sin., 68, 957-966.

Zhang L. S., and X. Q. Fang, 1988: Regional differentiation of the temperature fluctuation process in China (in Chinese). J. Beijing Normal Univ., 3, 78-85.

Zhao, Z. C., G. C. Xu, and K. L. Wang, 1990: Effect of urbanization on climate change (in Chinese). Meteor. Sci. Technol., 1, 7176, https://doi.org/10.19517/j.1671-6345.1990.01.012.

Zhou, L. M., R. E. Dickinson, Y. H. Tian, J. Y. Fang, Q. Li, R. K. Kaufmann, C. J. Tucker, and R. B. Myneni, 2004: Evidence for a significant urbanization effect on climate in China. Proc. Natl. Acad. Sci. USA, 101, 9540-9544, https://doi.org/10.1073/ pnas.0400357101.

Zhou, Y. Q., and G. Y. Ren, 2005: Identifying and correcting urbanization bias for regional surface air temperature series of north China over period of 1961-2000 (in Chinese). Climatic Environ Res, 10, 743-753.

— and —, 2009: The effect of urbanization on maximum, minimum temperatures, and daily temperature range in north China (in Chinese). Plateau Meteor., 28, 1158-1166. 